\title{
UMA ABORDAGEM NATURALISTA DA CONSCIÊNCIA HUMANA
}

Alfredo PEREIRA JÚNIOR*

- RESUMO: Abordo neste trabalho alguns dos principais problemas filosóficos concernentes a uma concepção naturalista da consciência humana, assim como algumas evidências disponiveis na neuropsicologia e neurofisiologia, sobre a relação entre atividade cerebral e experiência consciente. Inicialmente faço uma revisão sobre a definição de "consciência" seu estatuto filosófico e relação com os processos emocionais, e proponho três condições para sua atribuição a um sistema físico. Em seguida, identifico diferentes modalidades de consciência e seus correlatos cerebrais em diferentes escalas espaciais e temporais. Finalmente, discuto possiveis mecanismos biofísicos subjacentes aos processos conscientes.

- PALAVRAS-CHAVE: Consciência; neuropsicologia; neurofisiologia: epistemologia; mente.

\section{Introdução}

As tentativas de se entender a consciência humana como sendo um fenômeno integrante da natureza têm, ao longo da história do pensamento, conduzido a uma série de dificuldades. A maior delas possivelmente seria a dificuldade de se oferecer uma explicação causal, explicitando as condições necessárias e suficientes para que um sistema físico apresente o fenômeno consciência tal como este se apresenta para o ser humano.

* Professor adjunto - Instituto de Biociências/UNESP - Botucatu - apj@ibb.unesp.br 
Uma dificuldade simetricamente oposta é o risco de trivialização do conceito de consciência, decorrente da adoção de uma suposição panpsiquista (ou seja, que todo processo natural teria uma dimensão consciente). Para se evitar o panpsiquismo, é preciso estabelecer recortes na natureza física, limitando a atribuição de consciência aos sistemas vivos, ou a sistemas vivos que satisfaçam certas condições (por exemplo, domínio de uma linguagem simbólica). Os critérios para se estabelecer tal recorte são muitas vezes obscuros, ou mesmo preconceituosos, como quando se supõe a priori que apenas os seres capazes de se manifestar explicitamente sobre seus processos conscientes seriam conscientes

Uma outra dificuldade consiste em delimitar as semelhanças e diferenças entre a consciência animal e a humana. Enquanto os mecanismos neurobiológicos que suportam as atividades conscientes parecem ser muito semelhantes em várias espécies, especialmente entre os mamíferos, o modo como estes mecanismos se arranjam e interagem com o ambiente, no ser humano, parece ter características únicas, decorrentes de uma maior especialização dos mecanismos dedicados ao processamento de aspectos perceptuais, emocionais e motores, e da combinação dinâmica entre tais mecanismos.

A emergência da linguagem como meio de comunicação interindividual, em sua forma típica da espécie humana, seria então um elemento diferenciador importante. Nesta perspectiva, embora não se considere a existência de consciência como um privilégio da espécie humana, pode-se atribuir à consciência humana uma nova modalidade de existência, que não seria encontrada em outras espécies, a "consciência de ser consciente" ou autoconsciência. Ao mesmo tempo, considera-se que outras espécies compartilhem com a humana outras modalidades de processamento, o que torna o estudo do cérebro e da cognição nestes animais, em áreas como a psicobiologia, neurobiologia cognitiva e etologia, de grande utilidade para se entender aspectos homólogos da consciência humana.

\section{A Definição da Consciência e seu Estatuto Filosófico}

A definição da consciência constitui um problema clássico. Libet (1987) nota que
(..) O termo "consciência" tem sido livremento omprogfado part dellmittar vât: os significados diferentes, ou diferentes aspectos da funcuno contubrul nos humn

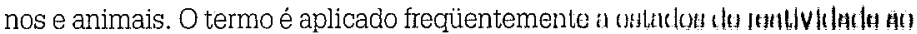
ambiente - estar consciente ou em coma, desperto ou uclomuuldo... Lithlit estados podem ser descritos em termos comportamentais, obsorvanila na o) humano ou animal.

Tentativas de se prover uma definição comportamental da cons= ciência originaram o conceito de awareness (sem tradução no portu* guês). O processo que conduz à awareness começa com um ato ou atos de atenção do organismo, recebendo sinais do ambiente, processando os mesmos de um modo coerente, e usando os resultados para informar ações futuras no mesmo ambiente. Todos estes passos podem ser identificados, e os diversos fatores envolvidos podem ser medidos em experiências científicas. Nas análises desses resultados, relações funcionais diversas entre percepção, atenção, memória e ação foram propostas.

Contudo, a partir do trabalho de Chalmers (1996), muitos pesquisadores atuais vieram a assumir uma distinção entre awareness e consciência, pois a consciência incluiria, além do processo que gera a awareness, também a experiência de um mundo fenomenal (um conceito bem discutido na tradição filosófica, p. ex. em Kant e Husserl) ou um "como é sentir-se em tal situação", que caracteriza a chamada "perspectiva da primeira pessoa", ou o "aspecto subjetivo" da experiência consciente (Chalmers, 1996).

Tanto o conceito de "mundo fenomenal", quanto os de "perspectiva de primeira pessoa", e de "aspecto subjetivo" da consciência têm em comum a suposição relativa à existência de estados qualitativos típicos da consciência, os famosos qualia. No contexto da tradição dualista cartesiana, os qualia são "qualidades secundárias", que não teriam existência objetiva (ao menos, nas categorias conceituais da física clássica, como na categoria da extensão espacial). Contudo, de uma perspectiva não dualista, os estados qualitativos da consciência podem ser relacionados a estados físicos do cérebro a serem empiricamente identificados, definindo-se assim uma zona de intersecção entre fenômenos subjetivos e objetivos (Pereira Jr., 2001b).

Seria adequado para o estudo neurobiológico da consciência que a mesma não fosse definida em termos dualistas, que já pressupõem de antemão a impossibilidade de seu estudo científico. Sem dúvida, devemos concordar com Chalmers e outros filósofos da mente sobre a realidade dos estados qualitativos que caracterizam o mundo 
fenomênico, porém sem fechar prematuramente as portas para o estudo dos mecanismos físico-biológicos que os suportam.

As filosofias materialistas e reducionistas, que postulam a identidade cérebro-mente, a eliminação do vocabulário psicológico ou a dedução da psicologia a partir da física, têm sistematicamente fracassado no projeto de se estudar a experiência consciente, ou de correlacioná-la com mecanismos neurobiológicos. Não insiro o presente trabalho nesta tradição, mas sim em uma visão naturalista nãoreducionista (Pereira Jr., 2001b), que procura trabalhar com os resultados empíricos das diversas ciências da natureza que se aplicam ao estudo do cérebro/mente, sem propor uma redução conceitual, ontológica ou metodológica da psicologia à biologia, ou da biologia à física.

Para isso é imprescindível reconhecer que o cérebro trabalha simultaneamente em múltiplas escalas espaciais e temporais, e que cada disciplina que o estuda tem uma ferramenta adequada para o acesso empírico e descrição conceitual de um determinado nível de organiza ção e atividade (Pereira Jr., 2001a). Os diversos niveis seriam portanto complementares e não contraditórios entre si, o que vem a demandar uma cooperação inter, multi ou transdisciplinar, para se realizar sinteses teóricas que permitam uma melhor compreensão da função cerebral como um todo.

Dadas as limitações tanto das teorias dualistas (seja as que concebem cérebro e mente como duas substâncias distintas - dualismo de substância - seja as que os concebem como uma única substância com propriedades opostas - dualismo de propriedades), quanto das teorias da identidade cérebro-mente, é preciso que se conceba em novas bases a relação entre cérebro e consciência, ou melhor, é preciso que se desenvolva uma abordagem dialética do cérebro/mente, que evite a camisa de força das teorias dualistas e da identidade. Estas abordagens, apesar de opostas entre si, têm em comum uma concepção não-dialética do cérebro/mente, que são concebidos como idênticos ou como irredutivelmente opostos. Na perspectiva dialética, ao contrário do que ocorre no dualismo e no reducionismo, os aspectos subjetivo e objetivo, de primeira e terceira pessoa, da experiência fenomenal e do mundo físico, não são vistos como contraditórios, mas como opostos que se complementam. O mesmo se aplica à relação entre as diversas disciplinas que se especializam no enfoque de cada aspecto.
O que torna possível não só correlacionar (empiricamento) como também entender (racionalmente) a relação entre atividado corobral o experiência consciente é a ocorrência de semelhanças de forme (homeomorfismos, ou correspondências estruturais) entre ambas, ou seja, entre relatos feitos por sujeitos humanos sobre seus conteúdos de consciência durante uma atividade cognitiva, e a concomitante observação da atividade cerebral feita pelos neurocientistas cognitivos com o recurso das tecnologias apropriadas. Não se trata, decerto, de um isomorfismo (igualdade de forma) devido à razão (discutida mais adiante) de que os correlatos cerebrais da experiência consciente se encontram distribuidos em diversas escalas espaciais e temporais, que seriam parcialmente descontínuas diante da observação de terceiros, ao passo que a experiência consciente se apresenta, para os sujeitos normais, como um fluxo unitário e contínuo

\section{Introspecção e o Problema da Consciência Animal}

Diversos filósofos da mente têm argüido, com razão, que os processos conscientes só são diretamente acessiveis para o próprio sujeito da experiência. Contudo, ao contrário do que alguns deles argumentam, este não seria um obstáculo intransponível para o seu estudo no contexto das ciências empíricas. Para contornar esta dificuldade, uma sofisticada metodologia tem sido desenvolvida pela neurociência cognitiva (ver Frith, Perry \& Lumer, 1999). Tal estudo cientifico requer, além de medidas da atividade cerebral durante processos conscientes, também os relatos dos sujeitos sobre seus conteúdos de consciência. Como só dispomos de relatos feitos por humanos, no estudo da consciência animal precișamos de uma suposição adicional, permitindo inferir que os tipos de experiência consciente nestes animais se correlacionam com os mesmos tipos de atividade cerebral com as quais eles se correlacionam em humanos.

Neste sentido, a consciência animal é uma entidade inobservável para o cientista, na mesma medida em que as partículas subatômicas o são na física. Contudo, existe no estudo da consciência animal a vantagem de que o cientista pode comparar os estados de consciência presumidos para um animal com seus próprios estados de consciência, e deste modo imaginar como seriam os processos conscientes 
desses animais. No caso dos inobserváveis da física a situação é mais difícil, requerendo o recurso à abstração em lugar da imaginação, mas nem por isso o caráter científico destes estudos é questionado. A postulação de entidades inobserváveis se tornou uma rotina na física das partículas e na astrofísica, o que tem gerado um grande debate entre os filósofos realistas e empiristas sobre a natureza destas entidades. Por outro lado, na psicologia e neurociência, devido a preconceitos filosóficos e metodológicos (hoje injustificáveis perante as novas tecnologias), e também à dificuldade intrínseca de estudo, foi comum negar um estatuto científico ao tema da consciência

Na primeira metade do século XX, os filósofos e neurofisiologistas costumavam contornar os problemas do estudo da consciência através de uma distinção conceitual entre sensação e percepção. A sensação era concebida meramente como uma sensibilidade ante os estímulos, medida em termos da resposta comportamental observável e das medidas de atividade neuronal disponiveis. A percepção, por sua vez, era concebida como um processo de nível superior, não sendo objeto de estudo da ciência, mas sim da filosofia fenomenológica. Os psicólogos gestaltistas e Teuber (1960) estão entre os primeiros que questionaram a separação conceitual estanque entre sensação e percepção. Mesmo na atualidade, embora muitos neurocientistas explicitamente neguem a separação estanque entre funções cognitivas elementares e funções "superiores", não é raro que a antiga distinção seja eventualmente revivida na interpretação de resultados experimentais.

A aparente inconsistência é possivelmente resultado de uma falta de compreensão da continuidade entre os processos fisiológicos desencadeados pela estimulação física no cérebro e os resultados finais, conscientes, do processo de percepção. Embora nem toda informação processada no cérebro se torne consciente, a parte que se torna consciente não é processada independentemente dos processos sensoriais, mas de alguma maneira se sobrepõe aos processos sensoriais nas mesmas partes do cérebro onde estes processos ocorrem.

Griffin $(1976,1984)$ apresentou vários argumentos em prol da realidade da consciência animal. Uma justificativa para isso seria a seguinte: se para nós a experiência sensorial implica experiências conscientes; por que não assumir o mesmo para outros indivíduos humanos, e para espécies que têm um sistema perceptual semelhante? Uma vez que a barreira entre sensação e percepção consciente tenha sido derrubada para nós mesmos, manter isto para outros indivíduos e espécies parece ser injustificado.
Mesmo considerando a força de argumentos como os de Griffin, a metodologia do estudo científico da consciência animal ainda é uma questão controvertida. Os adversários deste projeto, se não puderem argumentar pela inexistência de consciência em outras espécies, muitas vezes passam a argumentar de uma perspectiva cética, dizendo que mesmo que ela exista não pode ser provada. Mas não parece haver razäo pertinente para se exigir tal prova, pois neste caso todas as ciências que lidam com entidades inobserváveis também deveriam ser intimadas a fornecer provas irrefutáveis da existência das mesmas.

Sendo assim, é perfeitamente válido que a metodologia utilizada pela neurociência cognitiva, no estudo da consciência, faça uma suposição da semelhança entre estados acessíveis ao sujeito da experiência e estados experienciados por terceiros. Uma vez aceita esta suposição, o trabalho científico se faz de modo equivalente a todas as outras ciências empíricas, realizando-se uma série de medidas, busca de correlações significativas, discussão dos resultados e inferência de conclusões. A partir deste momento, a avaliação destas pesquisas deve ser feita em termos de sua proficuidade e relevância teórico/ prática, que com certeza revertem em favor das suposições metodológicas que as tornam possiveis.

\section{Emoções e Consciência}

A possibilidade de existência de processos emocionais inconscientes implica em uma desvinculação relativa entre teoria da consciência e teoria das emoções: enquanto os processos conscientes, como quer Damasio (1996), sempre seriam acompanhados de emoções, seria possível haver emoções não acompanhadas de consciência.

A parte inconsciente da atividade cerebral tem sido abordada em estudos neurocognitivos através do paradigma da emoção inconsciente, proposto por LeDoux e seu grupo (LeDoux, 1996). Os sistemas neuronais que apóiam processos conscientes estão amplamente conectados com os sistemas que apóiam processos emocionais, porém os estudos de LeDoux (que neste aspecto se opõem à proposta de Damasio) têm mostrado que em determinados casos consciência e emoção podem ser dissociadas. Segundo a proposta de LeDoux, exis tem dois caminhos de processamento das emoções: um primeiro, pelo qual a informação aferente é transmitida diretamente do tálamo/ 
hipotálamo para a amígdala, geraria as emoções inconscientes, como no caso de condicionamento por mensagem subliminar; e um segundo, onde a informação aferente é processada por sistemas neocorticais e pelo hipocampo antes de atingir a amígdala, gerando então uma emoção com conteúdo consciente. Para outros autores (Panksepp, 1999; Brandão et al., 1999), o processamento emocional envolveria ainda um circuito subcortical, incluindo a substância periaquiductal cinza e o coliculo inferior, que atuariam em conjunto com a amígdala.

A relação entre pensamento consciente e emoções pode ser vista como de complementaridade, e também de modulação do fluxo de pensamento pelas reações emocionais desencadeadas (e vice-versa) Muitas vezes, ao se pensar conscientemente a respeito de um determinado assunto são deflagradas reações corporais e emocionais, que servem como uma realimentação do próprio processo de pensamento. Às vezes tal realimentação é negativa, levando à inibição do processo (por exemplo, quando uma pessoa em estado depressivo tenta executar uma tarefa cognitiva). Ás vezes a realimentação é positiva, vindo a reforçar a linha de pensamento (por exemplo, quando uma pessoa está "caminhando e cantando e seguindo a canção", como é dito na famosa canção de Geraldo Vandré). Também os processos de pensamento sem ação externa tendem a ser acompanhados de reações emocionais, que fornecem ao organismo um avaliação prévia das possíveis conseqüências de se colocar em prática tais pensamentos.

O estudo de emoções na neurociência cognitiva tem se desenvolvido principalmente pela identificação dos mecanismos bioquímicos (transmissores e receptores de membrana, neuromoduladores) envolvidos nos diversos tipos de reações emocionais. Contudo, uma limitação do estudo das emoções a tais mecanismos constitui uma postura reducionista, que só vem a beneficiar segmentos da indústria de medicamentos, que pretendem vender drogas de atuação bastante específica como se as mesmas fossem por si só soluções para problemas emocionais complexos.

Embora uma seção sobre emoção estivesse presente em muitas coletâneas de estudos neurocientíficos desde os anos setenta, sua abordagem quase sempre se resumia à identificação das áreas cerebrais e mecanismos bioquímicos envolvidos. Uma adequada conceptualização dos fenômenos emotivos é tarefa difícil, e a compreensão da correlacão entre a base neuronal de emoção e sua fenomenologia ainda é uma área incipiente na neurociência afetiva e áreas afins (como a neuropsicofarmacologia e a psiquiatria biológica). Uma abordagem mais satisfatória requer modelos teóricos amplos, capazas de acomodet a miríade de resultados particulares sobre funçöos ospocfficne do trane missores, moduladores e receptores que abarrotam as roviatak clontlft cas da área. Uma proposta promissora de um modelo tobrlco dosto tipo parece ser a de Changeux (ver Changeux and Dahene, 2000), Changeux and Edelstein, 2001), que incorpora à neurociência o conhecimento sobre mecanismos de regulação alostérica entre proteinas (resumidamente, interações entre três ou mais compostos moleculares, p. ex., a, b e c, em que a regula c através da ativação de b), estudados por ele desde a década de 1960.

A possibilidade de se obter conclusões mais interessantes sobre a relação entre consciência e emoção depende de um melhor entendimento dos mecanismos cerebrais subjacentes a cada um dos dois fenômenos. Na hipótese apresentada ao final deste artigo, admite-se que os fenômenos sejam mediados por diferentes grupos de receptores de membrana, vindo a mobilizar diferentes caminhos de transdução de sinais dentro das células neuronais. Para os processos de percepção consciente, adoto como modelo a fisiologia do receptor ionotrópico NMDA, enquanto para os processos emocionais adoto como modelo a interação alostérica entre receptores metabotrópicos, neuromoduladores e G-proteínas. Para processos em que percepção e reação emotiva ocorrem conjuntamente, proponho a hipótese de uma confluência de processos intracelulares deflagrados por ambos os mecanismos acima citados.

\section{Três Critérios para a Consciência}

Como uma grande parte da atividade cerebral é inconsciente, qualquer teoria neurobiológica da consciência precisa apresentar critérios para distinguir os mecanismos que são cruciais para os processos conscientes, daqueles cuja ativação produz apenas processos inconscientes. Tais mecanismos não dizem respeito à estrutura cerebral (isto é, não se trata de critérios anatômicos), mas sim a tipos de funÇões cerebrais que suportam processos conscientes. Apresento aqui três critérios que me parecem básicos para distinguir estas funções.

Uma primeira condição geral para a existência de consciência deriva do trabalho do etólogo pioneiro von Uexkull (1934), que usou o termo "ciclo funcional" para caracterizar a relação sistemática entre 
percepções e ações de organismos, em um determinado ambiente. O sistema nervoso dos animais - das células nervosas primitivas distribuídas ao redor do tubo digestivo até a massa cinzenta protegida por um crânio - executa duas funções básicas, a de apreender sinais do corpo e do ambiente do animal, e controlar ações adaptativas do corpo no ambiente.

Em sistemas nervosos primitivos, as conexões entre células perceptivas e motoras são diretas, de acordo com o modelo do "arco reflexo". Nestes sistemas, parece não existir a possibilidade de ocorrência de funções que dêem suporte a processos conscientes. $\mathrm{Na}$ medida em que o sistema nervoso se torna mais complexo, ao longo da evolução das espécies, áreas especializadas emergem, inclusive mediando as células perceptuais e motoras. Dois tipos de processos referentes vêm a ocorrer: a percepção das conseqüências externas das ações, e por meio de sinais internos que vão do sistema motor para o sistema perceptual (mais tarde chamados de "descarga corolária"), constituindo o ciclo funcional (von Uexkull, 1934).

Em ciclos funcionais recorrentes, os organismos têm percepções que informam suas próximas ações, que influenciam suas próximas percepções, e assim por diante. Em conseqüência, se constrói um "mundo interno" ("umwelt"), tornando possivel a existência de consciência. Nesta perspectiva, que identifica a possibilidade de consciência com a recorrência dos ciclos funcionais de um organismo biológico dotado de um sistema nervoso diferenciado, os estados e processos conscientes seriam representações pragmáticas (ver Pereira Jr., 1999) da situação de um organismo ativo, com um determinado corpo, vivendo e se comportando em um determinado ambiente. Assim, a primeira condição geral de possibilidade da consciência seria a ocorrência de ciclos funcionais.

O ciclo funcional define estados presentes de consciência, porém o processo consciente - a julgar pela modalidade de consciência humana - envolve uma duração temporal, que inclui as dimensões do passado e do futuro. De fato, o feedback entre ação e percepção permite que se estabeleça um processo coerente de aprendizagem, segundo o princípio (Lei de Hebb) de que as conexões que foram úteis para comportamentos adequados são reforçadas. Para suportar esse processo de aprendizagem, novas especializações surgem entre a percepção e a ação, tornando possivel um sistema de memória e também a eleboração sistemática de antecipações das ações.
James (1890) concebeu a dinâmica espaço-temporal do mundo fenomênico como um "fluxo de consciência", no qual a posição singular do "sujeito" das experiências é caracterizado como um "aqui e agora". O fluxo é constituído pela sucessão de eventos, constituindo as noções de passado, presente e futuro. Os mecanismos cerebrais subjacentes ao fluxo da consciência são razoavelmente conhecidos nos mamíferos - em especial nos primatas -, mas é possivel que em outras espécies tal fenômeno cognitivo seja suportado por outras estruturas e funções relativamente mais simples.

No sistema perceptual de mamiferos há caminhos de realimentação, referidos por Edelman (1989) como "sinalização reentrante" (reentrant signaling) entre áreas sensoriais. Presumivelmente, tal sinalização teria o papel de deflagrar, através do mecanismo da atenção, o processo de consciência perceptual, correspondendo ao momento do presente. Também comporia o momento presente uma retenção de traços do passado, através dos mecanismos de memória distribuidos ao longo do neocórtex e sistema límbico (Squire, 1992), e uma protensão voltada para o futuro (ver o esquema proposto por Edmund Husserl em Pereira Jr., 1990), relacionada com os mecanismos de "prospecção", os quais se localizariam em uma rede que inclui áreas corticais parietais e pré-frontais (Rainer, Rao and Miller, 1999; Burgess, Quayle and Frith, 2001).

A consolidação de traços da experiência passada depende diretamente da função hipocampal, em suas conexões com o córtex entorhinal. Também foram identificadas conexões do sistema límbico para áreas associativas temporais e parietais, e destas para áreas frontais (ver Goldman-Rakic, 1987, para o caminho frontal-parietal). Essa rede de conexões possivelmente suporta, a partir de redes de osciladores temporais presentes nos neurônios, a experiência de duração temporal, que faz parte da consciência. Portanto, considero como um segundo critério para a consciência a existência de mecanismos que dêem suporte à experiência de um fluxo de eventos, que constitui o espaçotempo fenomênico.

Como consequiência da especialização de áreas cerebrais durante a evolução das espécies, o funcionamento cerebral veio a ocorrer de forma distribuida, em que cada subsistema executa parte da função global, entrando em relações de cooperação e conflito com os demais. Portanto, em um sistema deste tipo é inútil procurar por uma única estrutura do cérebro que seria a "sede" da consciência. Uma aborda- 
gem adequada dos mecanismos cerebrais que suportam o processo consciente deve necessariamente considerar a complexidade estrutural e funcional do cérebro. Os principais aspectos dessa complexidade são o processamento distribuido entre subsistemas espacialmente distintos, e a existência de atividade em múltiplas escalas espaciais (do nível dos íons até o nível do cérebro como um todo) e temporais (diferentes dinâmicas temporais, combinando processos na escala dos milisegundos com processos na escala da vida do individuo).

O processo consciente seria, portanto, fruto da atividade cerebral em múltiplos subsistemas, e múltiplas escalas espaciais e temporais. Constitui erro metodológico procurar correlatos cerebrais da consciência restritos a uma determinada região, ou a uma única escala espacial e/ou temporal, ou a um determinado tipo de processo físico. A multiplicidade dos correlatos cerebrais certamente está estreitamente relacionada com a multiplicidade das experiências conscientes que nós temos. Usando uma conhecida metáfora, o "teatro da consciência" (Baars, 1997) teria então muitos palcos em que muitos atores desempenham seus papéis simultaneamente, sucessivamente e concorrentemente. Nesta visão, aspectos diferentes da consciência seriam apoiados por diferentes subsistemas e níveis de atividade cerebrais inter-relacionados (como sugerido por Roy John, Easton e Isenhart, 1997; Smythies, 1997). Qualquer estrutura do cérebro que presumivelmente tenha um papel para a consciência deve ser - de acordo com os critérios anteriores - uma estrutura que participe em um ou mais ciclos funcionais, e que permita a composição de um espaço-tempo fenomênico. Como se faz então a integração destas múltiplas estruturas e respectivas funções, para se gerar um fluxo unitário de consciência?

Dennett (1991) se referiu a um processo de montagem em série, a partir de um processamento distribuido. Vários neurocientistas, na última década, lançaram a idéia de uma "ligação" (binding) neuronal que suportaria o processo consciente (Crick, 1984, a partir das evidências obtidas por Gray and Singer, 1989; Hardcastle, 1994). Essas idéias são interessantes, mas não seriam suficientes para se resolver a questão, uma vez que em todos sistemas distribuídos surgem conflitos funcionais que podem levá-los à imobilidade e perda de adaptabilidade ao ambiente. A relação entre conflito sistêmico e consciência é muito importante: toda tarefa que possa ser executada de modo automático ou algorítmico - isto é, toda tarefa que não envolva conflito sistêmico - pode ser realizada de modo inconsciente pelo cérebro (Young, 1993)

Portanto, existe aparentemente uma relação íntima entre o processo consciente e a resolução, pelo cérebro, de tarefas cognitivas que envolvem conflito sistêmico. Dada a complexidade cerebral, onde cada um dos bilhões de neurônios funciona como um processador de informação, toda tarefa perceptual e comportamental, durante o período em que estamos acordados, envolve tais conflitos. Com vista a este fato, é necessário acrescentar, como o último critério para a consciência, a existência de mecanismos capazes de resolver os conflitos sistêmicos, integrando a atividade distribuída em um fluxo espaçotemporal unitário (esta hipótese foi formulada e está expostá detalhadamente em Rocha, Pereira Jr. e Coutinho, 2001).

\section{Múltiplas Modalidades de Consciência}

A consciência acontece em diferentes graus e tipos (ver Pereira Jr., 1998; Shanon, 1997). Assim, no ciclo circadiano, o estado de vigília e o sonho presumivelmente se compõem de diferentes estados ou modalidades de consciência (ver Llinas \& Ribary, 1994; Hobson, 1994). Outra evidência neste sentido é encontrada no desenvolvimento humano: as crianças não nascem com o grau de autoconsciência típico de adultos, mas o alcançam progressivamente. Na análise comparativa do comportamento animal, tem sido discutido (Griffin, 1976, 1984) que alguns tipos de comportamento implicariam na existência de processos conscientes que os suportam, processos estes que seriam diferentes da consciência humana. O mecanismo de ecolocação em morcegos envolve um ciclo funcional no qual um som é emitido pelo animal, se reflete em objetos do ambiente, e então é percebido. Aparentemente esse processamento de informação ligado a uma ação inteligente no ambiente deve gerar um tipo de consciência que não encontra análogo nas formas de consciência perceptual humana.

Diferentes graus e modalidades de consciência presumivelmente coexistem, do mesmo modo como ocorreria uma justaposição de estruturas e funções cerebrais ao longo do processo evolutivo, como foi proposto ao final do séc. XIX por Hughlings-Jackson. Aparentemente a consciência humana abrangeria boa parte deste espectro, com a 
provável exceção de algumas modalidades perceptuais, como a referida ecolocação - enquanto a consciência em outras espécies animais provavelmente apresentaria limitações relativamente à consciência humana, por thes faltar dterminados niveis de processamento abstrato e de auto-reconhecimento individual e social, derivados do domínio da linguagem simbólica.

Sugiro que as modalidades de consciência possam ser classificadas em cinco grandes categorias (originalmente discutidas em Pereira Jr, 1998):

\section{Consciência Perceptual}

Este primeiro nível foi chamado pelos neurocientistas de "consciência básica" (Edelman, 1989) e awareness (p.ex., visual awareness, Crick, 1994). A consciência perceptual é dirigida a um objeto ou processo no ambiente do animal, o qual é tanto foco da percepção quí:ito da ação. Deste modo, processos cerebrais básicos de consciência já executam integrações sensório-motoras complexas; alimentar-se, por exemplo, é muito mais que somente ingerir, digerir e eliminar resíduos do alimento. É um comportamento que envolve (entre outras coisas) distinguir entre o que é comida e o que não deve ser ingerido. Para se realizar tal distinção é preciso obter informação sobre seres existentes no ambiente, e comparar tal informação com padrões internos (inatos e aprendidos). Estas operações se dão em sua maior parte de modo inconsciente, porém a julgar pela experiência humana - o único padrão de referência que possuímos para avaliar os processos conscientes -, em um determinado momento do processamento os resultados do julgamento emergem à consciência na forma de sensações de apetite ou aversão.

Está além das possibilidades do método científico, neste momento, identificar um ponto na escala filogenética em que a consciência perceptual emerge. Por exemplo, os peixes têm estruturas cerebrais que integram processos de percepção e ação (o tectum óptico, uma estrutura homóloga ao colículo superior dos mamíferos). Eles podem distinguir claramente entre aquilo que lhes serve de comida e o que não lhes serve, mas permanece uma questão aberta saber se eles estão conscientes sobre o que é comida e o que não é.

Os subsistemas do cérebro envolvidos na geração de consciência perceptual seriam as áreas sensórias corticais primárias, como origi- nalmente sugerido por Lashley (1951), áreas associativas nos animais que as possuem, e estruturas subcorticais que executam integraçăo intermodal e influenciam no controle de ação. Por exemplo, foi sugerido que o colículo superior estaria relacionado à consciência (Strehler, 1991). Em humanos, tal hipótese está limitada pelo pequeno tamanho e limitação de função de tal estrutura. Porém, a indicação de um possivel papel do colículo superior para a consciência perceptual em outras espécies se deriva de estudos sobre blindsight em humanos Pacientes com lesão unilateral da área cortical visual primária (chamada de córtex estriado ou V1) perdem a consciência visual de estímulos localizados no campo visual contralateral, na área correspondente ao campo receptivo da população de neurônios perdida. Contudo, quando este estímulo se move a uma determinada velocidade, alguns pacientes reportam uma vaga percepção visual do mesmo (ver Weiskrantz, 1997). Entretanto, quando o estímulo não está se movendo, os pacientes podem permanecer atentos ao mesmo (capazes de fornecer informação sobre o estímulo), mas não são conscientes do estímulo (por isso o fenômeno foi denominado "visão cega"). Relatos dos pacientes indicam que a intensidade e a qualidade da percepção do estímulo em movimento são bem mais enfraquecidas que em situações normais. No hemisfério lesionado de tais pacientes, o único caminho visual para o controle da ação que permaneceu foi o coliculo superior, e sendo assim pode ser levantada a hipótese de que a integração percepção-ação mediada pelo colículo superior pode produzir algum grau de consciência em outros animais.

Outra estrutura subcortical que foi implicada em uma forma básica de consciência é o tálamo. Wilber Penfield, realizando pesquisa em pacientes submetidos a cirurgias no cérebro, nos anos 50 do século passado, descobriu que a consciência é bloqueada (i.e., pacientes entram em estado de coma ou semelhante ao coma) quando é aplicada uma leve pressão ao sulco médio do tálamo esquerdo, e retorna quando a pressão é removida. Por outro lado, determinados conteúdos sensoriais seriam produzidos (alguns bastante elaborados) por meio de uma pequena excitação elétrica no sistema tálamo-cortical, de acordo com um trabalho por ele publicado anteriormente (Penfield and Boldrey, 1937).

$\mathrm{Na}$ "hipótese de holofote" de Crick (searchlight hypothesis, 1984), a ativação talâmica induziria uma sincronia oscilatória em assembléias do córtex sensorial que teria, segundo o autor, o papel de "ligação" (binding) de componentes do processo perceptual, gerando uma cons- 
ciência perceptual unitária. Esta hipótese é consistente com a descoberta de sincronias oscilatórias em potenciais evocados no córtex visual do gato, em freqüências na faixa dos $40 \mathrm{~Hz}$ (Gray e Singer, 1989). e mudanças de fase ao longo do córtex (ver Llinas \& Ribary, 1994).

O modelo intitulado ERTAS (em alusão ao sistema reticular), que é uma versão neurobiológica da teoria do Global Workspace de Baars (Baars, 1987; Newman e Baars, 1993), é mais detalhado e consistente que a hipótese de Crick. É proposto que o sistema reticular de ativação (do qual o tálamo faz parte) controle a atividade cortical e defina um estado geral de consciência. Os conteúdos da consciência seriam selecionados pela totalidade do sistema, em especial pelas regiões especializadas do neocórtex, segundo um principio computacional que seria o da capacidade limitada de processamento. Contudo, os dados disponíveis não parecem ser conclusivos sobre o papel de conexões tálamo-corticais na geração da consciência: elas podem apenas apoiar os mecanismos corticais necessários para as diversas formas de consciência, ou também prover um mecanismo seletivo que faça parte da determinação dos conteúdos, como querem Newman e Baars. Em ambos os casos, o tálamo é certamente um dos sistemas cuja atividade integrativa é necessária para a consciência perceptual.

Em primatas a consciência perceptual também está relacionada às áreas associativas corticais, sendo a área ínfero-temporal (Logothetis e Schall, 1989) crucial para a consciência visual de forma, e a área parietal posterior (Schacter, 1989; Goodale and Milner, 1992) crítica para os movimentos visualmente guiados. Quando uma destas áreas é lesionada em humanos, ocorre a deterioração de aspectos especificos da consciência perceptual. No caso da consciência visual, tais fenômenos são chamados de neglect (ver uma revisão de tipos de deterioração em Young, 1992; Kohler \& Moscovitch, 1997)

\section{Consciência Corporal}

Esta modalidade de consciência está voltada para a percepção de estados do próprio corpo. Ela compartilha os mecanismos neurais da consciência perceptual, porém também envolvendo novos tipos de feedback que suportam a formação da noção de um "eu corporal" autônomo e distinto dos demais seres presentes à percepção. Os mecanismos de feedback envolvem ciclos de reaferência corporal, ligados à geração de sensações corpóreas, sentimentos e emoções, os quais, em mamíferos, se relacionam à atividade do sistema límbico, mais precisamente o córtex cingulado anterior (Posner, 1994) e amígdala (LeDoux, 1994). Gray (1995) propôs que conteúdos da consciência seriam gerados por uma função de comparação centrada no sistema hipocampal.

O ciclo reaferente que produz consciência corporal foi descrito por Damasio (1996) em sua hipótese do "marcador somático": "no caso do dano de um tecido, o cérebro representa a mudança ocorrida no corpo, e dispara mudanças de estado corporais adicionais... É das mudanças de estados corporais subseqüentes que se formará o sentimento desagradável de sofrimento". Assim interpretada, a consciência corporal é mais do que uma representação de estados do corpo no cérebro; ainda de acordo com Damasio (1996), a experiência de uma emoção implica a existência de um ciclo no qual cérebro e corpo afetam um ao outro continuamente: "eu conceptualizo a essência do sentir (feelings - APJ) como algo que você e eu podemos ver através de uma janela que se abre diretamente sobre uma imagem continuamente atualizada da estrutura e estado de nosso corpo".

Na medida em que uma ativação do sistema límbico é envolvida neste tipo de ciclo funcional, então a emergência da consciência corporal na escala filogenética se reportaria ao surgimento dos répteis, quando o sistema límbico adquiriu configuração semelhante à atual (MacLean, 1990). Em mamiferos, a especialização do neocórtex conduziu à atribuição ao córtex somatosensorial de boa parte dos processos de reconhecimento dos estados corporais.

Os mecanismos de consciência corporal possivelmente evoluíram desde sua emergência reptilínea, até o ponto em que as alterações corporais envolvidas se tornaram bastante sutis, como por exemplo as expressões faciais que acompanham os estados emocionais, $e$ sensações como o frio na espinha e o arrepiar dos cabelos.

\section{Consciência Voluntária}

Este grau de consciência diz respeito à capacidade de decidir conscientemente sobre a execução de ações. Em muitas espécies animais, as decisões sobre ações são fortemente dependentes de fatores de origem genética e da aprendizagem prévia, o que não conta necessariamente contra a atribuição de uma decisão consciente a eles. A existência de consciência voluntária não se identifica com a existência 
de uma completa liberdade de escolha (free will), mas pode ocorrer nos quadros de um comportamento previamente condicionado.

Um exemplo familiar pode ajudar a esclarecer este ponto. Consideremos um cachorro que foi treinado para não entrar dentro de casa. O cachorro vê a porta aberta e percebe os odores atraentes de comida que vêm lá de dentro. Estes estímulos impelem o cachorro para entrar na casa; porém, ao mesmo tempo sua memória de experiências anteriores (entrou dentro de casa e foi punido) contribui para inibir aquele comportamento. A ação resultante dependerá do conflito entre estas forças opostas, que possivelmente mobilizam diferentes subsistemas cerebrais do animal. Considero que, neste exemplo, a decisão de não entrar na casa envolva uma modalidade de consciência, que seria a consciência voluntária.

A capacidade de tomar decisões que vão contra a tendência dos estímulos imediatos depende de processos de inibição de atividade neuronal nas áreas perceptuais, e também da existência de mecanismos de controle da ação relativamente independentes do processamento perceptivo. Nos mamíferos, a distinção entre áreas perceptuais e áreas motoras, em particular o papel funcional do sistema formado pelo giro cingulado, córtex premotor e motor, dão suporte à consciência voluntária. O aparecimento destas áreas, ao lado de mecanismos inibitórios do córtex prefrontal (correspondendo ao mecanismo de atenção seletiva; ver Posner, 1995) tornam possível que, mesmo se os estímulos sensoriais favorecerem um determinado comportamento, o animal poderá (conscientemente) decidir não executá-lo. Em animais que não têm estas especializações, as ações são mediadas através de estruturas subcorticais diretamente controladas por combinações de estímulos sensoriais: uma vez que os estímulos atinjam determinados limiares, os respectivos padrões motores que definem o comportamento diante de tal situação são deflagrados automaticamente. Estes animais, conseqüentemente, não possuiriam a modalidade de consciência aqui discutida.

\section{Consciência Abstrata}

Esta modalidade corresponde ao conceito de consciência como "representação de segunda-ordem", proposto pelos filósofos Rosenthal (1986) e Lycan (1987, 1995), ou à teoria da "consciência como um comentário", proposta pelo neurocientista Weiskrantz (1997). Trata-se de uma modalidade de consciência que opera com sinais que se referem a outros sinais pré-processados pelo cérebro. Esta segunda classe de sinais diz respeito a grupos de sinais, constituindo categorias abstratas que não correspondem diretamente a quaisquer grupos de objetos dados empiricamente. Por exemplo, em nível da consciência abstrata podemos nos reportar à classe das coisas que têm cor amarela, ou à categoria dos pares de coisas que mantêm relações de causa e efeito.

As categorias da consciência abstrata não devem ser necessariamente identificadas com as representações lingüisticamente formuladas, típicas da consciência humana; elas devem ser entendidas como representações de classes de objetos de acordo com características perceptuais e pragmáticas, podendo adquirir a forma de imagens ou signos não-linguísticos. Isto implica que a consciência abstrata teria uma estrutura proposicional, mas não necessariamente lingüística.

Na perspectiva de Weiskrantz, esta modalidade de consciência constitui um "comentário" que as áreas associativas do córtex produzem sobre a informação sensorial processada nas áreas primárias. 0 desenvolvimento do córtex prefrontal em primatas e cetáceos tornou possivel a formação de dois ciclos de processamento entre as áreas associativas do neocórtex; o primeiro é constituído por sinais que caminham no sentido forward, das áreas parietais e temporais para o córtex prefrontal, e o segundo ciclo caminha backward, das áreas frontais para as áreas posteriores. Estes ciclos se relacionam com as funções executivas (Stuss, Eskes \& Foster, 1994; D'Esposito \& Grossman, 1996), como a manipulação consciente da informação na memória de trabalho (Schacter, 1989; Jonides, 1995; Jonides \& Smith, 1997; Smith and Jonides, 1997), perseguição de metas e controle dos processos perceptuais por meio de mecanismos da atenção.

Um exemplo importante de estudo científico de uma forma de consciência abstrata em primatas não-humanos é o experimento de auto-reconhecimento no espelho (ver Gallup, 1970). Contrariamente à interpretação inicial dada ao experimento, tenho argumentado (Pereira Jr., 2000) que os resultados não implicam a existência de uma modalidade de autoconsciência nesses animais, mas decerto implicam o concurso da consciência abstrata para a resolução do problema. $O$ fato de que um animal possa classificar a imagem distal no espelho na mesma categoria dos sinais reaferentes proximais, e, por conseguinte, inferir que a imagem diz respeito aos seus próprios corpos, implica a capacidade de formação de classes abstratas de sinais e de uso das mesmas em um raciocínio voltado para a resolução de problemas. 


\section{Consciência de Si, ou Autoconsciência}

Esta modalidade é caracterizada pela consciência de ser consciente, ou pela consciência do "eu" (self), aqui concebido como uma construção histórico-cultural, lingüisticamente formulada, que expressa a unidade de um organismo individual. A formação de um conceito de self implica uma integração de uma multiplicidade de experiências distintas em uma unidade, o que requer três operações cognitivas: auto-referência simbólica; referir-se univocamente a esta unidade, e comunicação em primeira pessoa com outros seres semelhantes. Estas capacidades são satisfeitas pelos seres humanos, sendo discutível se organismos de outras espécies ou se máquinas seriam capazes de realizar estas operações cognitivas.

O conceito de self é suportado por uma ampla rede neuronal, envolvendo o sistema límbico e subsistemas corticais, incluindo as áreas clássicas da linguagem (áreas de Broca e Wernicke). Estes subsistemas cerebrais apóiam e são implicados na mediação do pensamento lingüisticamente formulado, em especial a forma de pensamento linguístico sem vocalização chamado de "fala interna" (inner speech; um termo originalmente usado por Luria (ver Luria, 1973) e discutido em Stuss \& Benson (1990), que desempenha papel central na vida mental do self. As áreas de linguagem têm conexões corticais diversas, recebendo informação aferente (o que permite que se façam declarações sobre estados do corpo e o mundo), e também informação sobre comportamentos planejados, o que permite a formulação das intenções. A parte crítica do sistema que suporta o conceito de self é provavelmente o córtex prefrontal, que está envolvido na coordenação de intenções e metas que guiam o uso da linguagem e outras formas de comportamento (ver Goldberg, 1990). Evidências neste sentido advêm principalmente de estudos dos correlatos neurológicos de distúrbios graves que afetem o sentido de self, como a esquizofrenia.

Até onde temos uma compreensão do desenvolvimento da linguagem humana, sabemos que é preciso interação social para que o organismo individual realize seu potencial genético. A formação do conceito de self parece ser uma parte deste processo, e deste modo a natureza e extensão de seu desenvolvimento dependeriam crucialmente do reconhecimento social do indivíduo biológico como um sujeito ético. Tal reconhecimento envolveria a simbolização do nome do indivíduo, a exibição de coerência de personalidade entre diversas experiências na sociedade, e a atribuição de direitos e responsabilidades para com os outros individuos. Assim sendo o self seria uma unidade composta neurobiológica, psicológica e sociocultural. Os indivíduos podem pensar sobre si mesmos como uma entidade independente como ocorre no famoso 'cogito' cartesiano, proposto como base para o conhecimento filosófico - mas esta independência seria fruto de um mal-entendido, como foi argumentado no debate filosófico clássico entre o cartesianismo e correntes divergentes, como a dialética de Hegel e a fenomenologia de Husserl

\section{Possível Mecanismo que Suporta a Experiência Consciente}

O progresso recente das neurociências tem mostrado que os processos cognitivos no cérebro ocorrem simultaneamente em múltiplas escalas espaciais e temporais, envolvendo diferentes tipos de sinais físico-químicos. Os três neurobiólogos que receberam o Prêmio Nobel de Medicina em 2000, Paul Greengard, Arvid Carlsson e Eric Kandel, estudaram os níveis moleculares e bioquímicos de articulação das funções cognitivas no cérebro. Estas pesquisas levaram a um melhor entendimento dos mecanismos sinápticos, de membrana e dos processos intracelulares de transdução de sinais que suportam a cognição, contrariando os clamores daqueles que acreditavam que o entendimento da função cognitiva do cérebro deveria se reportar principalmente ao nível macroscópico de atividade. As duas últimas décadas de pesquisa nas neurociências têm conduzido a uma mudança de paradigma, na qual os processos cognitivos são mais e mais correlacionados com processos que ocorrem em nível microscópico, na escala temporal de milisegundos, rompendo assim com pressupostos ingênuos de que tais mecanismos ocorreriam no mesmo nível de organização da experiência consciente humana (isto é, nivel macroscópico e escala temporal acima de $100 \mathrm{~ms}$ ). Entretanto tais descobertas $_{i}$ por exemplo a descoberta do papel dos transmissores dopamina e serotonina nos processos de aprendizagem e memória, não nos conduzem à conclusão de que os mecanismos subjacentes aos processos cognitivos sejam apenas quimicos e moleculares; pelo contrário, nos defrontamos com um panorama de complexidade, sugerindo que um entendimento adequado das funções cognitivas no 
cérebro deve cobrir simultaneamente diversos níveis de organização e suas interações.

Tomando como exemplo o sistema visual dos mamiferos, notamos que diversos tipos de processos, distribuídos em diferentes escalas espaciais e temporais, contribuem para que tenhamos experiencias visuais. A retina possui células especializadas para detectar padrões de informação nos fluxos de fótons, oriundos do ambiente, que a atingem. Tal informação é transduzida para padrões de atividade elétrica, que são conduzidos através do feixe de axônios daquelas células (isto é, pelo nervo óptico) até o tálamo. O tálamo está conectado com outras estruturas subcorticais, como a formação reticular, que induzem a produção de transmissores e moduladores capazes de controlar a atividade do sistema límbico e do neocortex, estruturas cruciais para a geração dos conteúdos da consciência. Portanto, o tálamo e as outras estruturas subcorticais alimentam o sistema límbico e o neocortex de uma variedade de padrões elétricos oriundos da interface com o ambiente, e de substâncias reguladoras; aqueles sistemas, por sua vez, realizam diversos processos a partir desses sinais, vindo a construir o mundo da experiência consciente.

Com certeza, parte da operação do sistema límbico e neocórtex se manifesta no nível macroscópico, em termos de padrões de atividade eletromagnética, que correspondem a padrões de fluxo sanguíneo para suas diferentes partes. Diversos tipos de eletrodos, internos e externos ao crânio, assim como bobinas que registram variações de campo magnético, têm sido utilizados para se estudar tais padrões macroscópicos de atividade, os quais muitos neurocientistas ainda acreditam constituir os correlatos últimos da experiência consciente.

Contudo, as correspondências entre atividade neuronal e atividade consciente assim obtidas são até o presente muito pouco precisas; elas abrangem apenas os diferentes estados de consciência (por exemplo, a distinção entre estado de vigília, sono profundo e sono $\mathrm{REM}$ ), e os tipos de cognição (modalidades perceptuais, mecanismos de atenção, funções executivas e motoras), mas não dizem respeito aos conteúdos da consciência (isto é, tal tecnologia não permite "ler o pensamento", inferir o que se passa na consciência de uma pessoa através de dados sobre sua atividade cerebral).

Nos últimos anos, foi também desenvolvida a técnica de imagem por ressonância magnética, a qual, em uma de suas versões (BOLD fMRI - que mede o nível de oxigenação do sangue circulante no cére- bro) permite identificar padrões macroscópicos de distribuição espacial do fluxo de sangue arterial. Também aqui se encontram inúmeras correlações entre tipos de processos cognitivos (realizados simultaneamente à medida da atividade cerebral) e a ativação de regiões específicas do cérebro; porém, assim como no caso das técnicas de medição eletromagnética, tais correlações são excessivamente imprecisas para constituirem explicações satisfatórias da cognição a partir dos processos cerebrais.

Uma característica central dos padrões de atividade macroscópicos relacionados com os processos cognitivos conscientes é a existência de coerência (ver Tononi, Edelman e Sporns, 1999). Isto significa que a distribuição espacial da excitação neuronal, ao longo do sistema nervoso central (SNC), apesar de ser extremamente dinâmica e variada ao longo do tempo, não tem caráter aleatório. A cooperação entre regiões relativamente distantes do SNC parece constituir requisito necessário, não só para a ocorrência dos processos conscientes, como também para a capacidade mais geral de resolução de problemas com base no raciocínio inteligente. Os modelos reducionistas, que pretendem explicar a atividade do cérebro a partir de um nível privilegiado de descrição (seja ele macroscópico ou microscópico), têm encontrado dificuldades ante as evidências de que o cérebro simultaneamente atua em diferentes niveis organizacionais.

Dadas as razões acima, um novo tipo de explicação da atividade cerebral se faz necessário, enfatizando a existência de complexas interações entre os diferentes niveis de processamento. Possivelmente tais interações apresentam características observadas em outros sistemas dinâmicos, como a existência de valores críticos para a interferência da atividade de um nivel de organização sobre outros. Os processos mentais corresponderiam à auto-organização do sistema cerebral, em suas interações com o corpo e o ambiente, sendo que no tocante ao cérebro os diversos niveis de organização - e respectivos modos de processamento da informação - seriam relevantes para se entender os diversos aspectos da cognição.

Retornando ao exemplo do sistema visual, sabe-se que seu funcionamento no SNC dos primatas requer a cooperação de ao menos quatro subsistemas:

a) as áreas visuais primárias, que recebem os sinais elétricos oriundos do tálamo, levando à ativação de suas redes neuronais na for- 
ma de um "mapa", que reproduz as relações espaciais entre os itens informacionais tal como estes atingem a retina (ou seja, existe um isomorfismo espacial entre tal mapa - chamado de mapa retinotópico - e o campo visual da retina);

b) as áreas visuais secundárias, caracterizadas por neurônios especializados em detectar aspectos específicos, e relativamente simples, da informação oriunda dos sensores periféricos, como cor, direção de movimento, aspectos da forma, etc.;

c) as áreas associativas parietal e temporal: a primeira é especializada em se identificar onde estão os objetos percebidos (e por isto é chamada de where pathway), e a segunda especializada em se identificar formas complexas, como formas de rostos de pessoas (e por isto é chamada de what pathway; veja-se Ungerleider and Haxby, 1994);

d) áreas específicas do córtex prefrontal, como a área dorsolateral, que codifica conteúdos da memória de trabalho (working memory), e a área de controle do movimento ocular (frontal eye field), que está envolvida com o processo de atenção visual.

Grande número de estudos recentes tem mostrado que a cognição visual envolve a cooperação desses quatro subsistemas (e ainda outras estruturas subcorticais, como o colículo superior), em termos de um processamento distribuido da informação, o qual, a partir da solução dos conflitos sistêmicos que sucessivamente ocorrem, vem a gerar uma experiência visual unitária, na qual os diversos aspectos processados em diferentes partes do SNC surgem integrados uns aos outros. Para se entender como tal integração ocorre, é necessário mudar a escala de observação, enfocando-se a função dos neurônios participantes dessas redes, e questionando-se por que a cooperação referida acima seria necessária para que determinados eventos venham a ocorrer nesses neurônios.

Um dos modelos existentes - para se explicar a relação entre os padrões de atividade macroscópica (eletroquímica e sanguínea) e a atividade celular microscópica dos neurônios - é o proposto por Rocha, Pereira Jr. e Coutinho (2001). O modelo se baseia na fisiologia do canal de ion controlado pelo receptor NMDA, que tem sido bastante estudado por seu possível envolvimento nos mecanismos de aprendizagem e memória. Quando o canal controlado pelo receptor NMDA se abre, permite a passagem de ions de cálcio, que controlam diversas funções no interior do neurônio. Assumimos que algumas dessas fun- ções se relacionam com o processo de consciência perceptual. Contudo, para que o canal NMDA se abra, é preciso que o neurônio receba sinais excitatórios sucessivos, em um curto intervalo de tempo. Por essa razão, o canal NMDA é considerado um "detector de coincidência", que seria de especial valor para os processos de aprendizagem associativa. Tais sinais seriam providos por meio da atividade cooperativa entre neurônios, o que demonstra a possivel relação desse mecanismo com os padrões de coerência mencionados acima.

Os íons de cálcio, como se sabe, têm outras funçōes importantes nos neurônios (e também desempenhando outras funções em outros tipos de células, como a célula muscular). Quando um sinal elétrico é enviado pelo axônio de um neurônio e atinge a fenda sináptica, faz com que íns de cálcio ali presentes rompam vesículos contendo subs tâncias transmissoras, as quais se ligam aos receptores de membrana do neurônio pós-sináptico. Neste momento ocorre um novo tipo de processamento de informação, baseado em mecanismos moleculares (isto é, na configuração de efetores e receptores, expressa na metáfora da "chave e fechadura"). Como se pode facilmente constatar, devido à existência de dezenas de diferentes tipos de transmissores, moduladores e receptores nas sinapses, o "código" que opera nesse nível do processamento é bem mais rico que o código utilizado na transmissão dos sinais elétricos entre os neurônios. Portanto, seria correto afirmar que as sinapses não "refletem" ou "representam", mas antes reconstroem os sinais oriundos do mundo externo.

O trabalho de E. Kandel, entre muitos outros estudos contemporâneos, tem mostrado que os mecanismos sinápticos ainda estão longe de constituir o "fim da linha" do processamento de informação cerebral. Logo em seguida à operação das sinapses, existem outros níveis de organização nos quais ocorrem outros tipos de processamento, que terminam por se entrelaçar de modo circular, envolvendo até a desinibição e expressão de genes contidos no núcleo dos neurônios. Os receptores chamados ionotrópicos, que se situam na membrana do neurônio pós-sináptico (em uma estrutura chamada de densidade póssináptica), controlam o fluxo de ions de sódio, potássio e cloro através da membrana, constituindo assim um mecanismo que determina a atividade eletromagnética da membrana, que é difusamente medida no nível macroscópico.

Além do receptor NMDA (ionotrópico que controla a entrada do $\mathrm{Ca}+)$, existem outros receptores cuja ação se dirige para o interior do neurônio, controlando os circuitos de processamento de informação 
chamados de "caminhos de transdução de sinais" (do inglês signal transduction pathways, ou STPs). Estes receptores são chamados de metabotrópicos, e muitos deles têm a capacidade de se ligar (consistindo em um caso de alosterismo) tanto com neuromoduladores presentes em nivel da membrana, quanto com G-proteínas internas aos neurônios, que controlam STPs.

O conhecimento sobre STPs é bastante recente, e ainda limitado a partes desses processos. Algumas simulações computacionais têm sido feitas, a partir do conhecimento parcial existente, para se tentar entender o que ocorre nesse nivel de organização. Sabe-se que o processamento de informação nos STPs envolve, além dos ions de cálcio que entram pelo canal NMDA e a atividade dos receptores metabotrópicos, também elementos compartilhados com o sistema endócrino, e fatores de crescimento celular (chamados de "fatores tróficos"). De acordo com o modelo proposto por A. Rocha, A. Pereira Jr. e F. Coutinho (2001), os STPs também seriam responsáveis pelo disparo de processos quânticos envolvendo elétrons (ou prótons) das proteínas envolvidas, como as proteínas kinases (que desempenham papel central nos STPs). A computação quântica constituiria um novo nível de processamento de informação, que permitiria uma comunicação não-local entre neurônios de diversas partes do cérebro, permitindo a solução de conflitos sistêmicos, e dando suporte aos estados conscientes e emocionais.

Nos sistemas cerebrais relacionados com a geração das "emoÇões" (mais precisamente, as sensaçōes de dor e prazer, medo e ansiedade, tristeza ou felicidade, etc.), como a amigdala e o hipotálamo, podemos conjecturar que os receptores metabotrópicos - que atuam em uma escala temporal mais dilatada que o NMDA, e inadequada para suportar os processos de percepção visual - participariam de agregados alostéricos com neuromoduladores de ação específica e Gproteínas, ativando ST'Ps que conduzem a outras modalidades de computação quântica, as quais sem dúvida se entrelaçariam com aquelas dedicadas à consciência perceptiva, gerando estados unitários nos quais as emoções se ligam a determinados objetos (p. ex., quando sentimos medo de ser assaltado por uma pessoa que estamos vendo à nossa frente, diferentemente da situação em que se tem medo sem um objeto definido).

Outros niveis de processamento possivelmente existentes, envolvidos na co-produção das funções cognitivas do cérebro e na interação cérebro - (restante do) corpo seriam: a) componentes dos STPs atingem o retículo endoplasmático e núcleo dos neurônios, levando à ativação de genes que possivelmente reporiam as proteínas necessárias para a manutenção dos próprios processos (em nível de sinapse, membrana e STPs) que conduziram à ativação desses genes. Criam-se assim ciclos de interação proteínasgenes, que podem durar por muito tempo na vida de um organismo individual, e que seriam, segundo Kandel, a base da memória de longo termo (p.ex., as lembranças que temos de fatos que ocorreram durante nossa infância). Sobre este aspecto, ver Guimarães (1997);

b) no processo de produção de proteínas ocorre, como nas demais células do corpo, o "dobramento" das cadeias lineares de aminoácidos para formar as proteínas. No cérebro, este processo seria controlado por um complexo processamento de informação, onde atuam não só a informação genética como outros fatores do ambiente celular (no caso, do ambiente neuronal e glial);

c) em alguns STPS, ou mesmo em nível do retículo ou do núcleo, seriam ativados processos de produção de neuropeptídeos que atuam não só como moduladores da atividade das sinapses, como também rompem a barreira cérebro-corpo, difundindo-se via circulação para outras partes do corpo (p.ex., já foram encontrados no sistema digestivo de ratos), possivelmente controlando um novo nível de processamento responsável por reações psicossomáticas.

\section{Duas Conclusões Provisórias}

A Neurociência Cognitiva tem propiciado o estabelecimento de uma série de correlações entre medidas da atividade cerebral, medidas comportamentais e processos cognitivos descritos através de modelos teóricos de natureza biológica e/ou informacional. A existência dessas correlações desautoriza visões filosóficas dualistas, em que cérebro e mente são concebidos como entidades distintas, ou como aspectos incompativeis de uma mesma entidade. Por outro lado, tais correlações não autorizam visões epistemológicas reducionistas, ou propostas ontológicas de identidade cérebro/mente, pois não revelam mecanismos causais suficientes para se determinar conteúdos mentais a partir do conhecimento da atividade cerebral e do comportamento. Portanto, minha primeira conclusão provisória é que a aborda- 
gem naturalista da consciência, aqui proposta, seria ao mesmo tempo não-dualista e não-reducionista.

A possibilidade de uma abordagem da consciência em termos da informação e computação quânticas, por sua vez, sugere uma outra conclusão mais ousada, a respeito da natureza do fenômeno mental. Devemos considerar seriamente modelos em que os processos mentais estariam estreitamente relacionados com fenômenos microscópicos, como o movimento coerente de íns através de canais de membrana neuronal. Este tipo de modelo aponta questões epistemológicas bastante densas, que não terei condições de discutir neste artigo, como por exemplo: não seria adequado representar os processos mentais em um espaço de estados de muitas dimensões, como na física quântica, em vez do espaço-tempo quadridimensional da mecânica clássica/relativística? Portanto, podemos evidenciar o valor heurístico da abordagem naturalista da consciência, ao levantar uma nova concepção da mente e dos instrumentos a serem utilizados em seu estudo.

\section{Agradecimentos}

Stephan L. Chorover (MIT), que supervisionou meu estágio de pós-doutorado, quando foi realizada a primeira versão deste trabalho; FAPESP, pela bolsa para o estágio, e CNPq, pela atual bolsa de produtividade em pesquisa.

PEREIRA JÚNIOR, A. A naturalistic approach to human consciousness. Trans/ Form/Ação, (São Paulo), v.26 (2), p.109-141, 2003.

- ABSTRACT: This essay discusses some central philosophical problems concerning the naturalistic concept of consciousness, as well as evidence from neuropsychology and neurophysiology regarding the relation of brain activity and conscious experience. Initially I review the problem of defining "consciousness", the philosophical approach to the phenomenon and its relation to emotional processes. The next step is a proposal of three conditions for the attribution of consciousness to physical systems. In the following section, I identify different modalities of consciousness and their respective neural correlates in different spatial and temporal scales. Finally, I discuss possible biophysical mechanisms underlying conscious processing.

- KEYWORDS: Consciousness; neural correlates; neuropsychology; neurophysiology; emotion.

\section{Referências bibliográficas}

BAARS, B.J. (1997). In the Theater of Consciousness. New York: Oxford University Press.

BAILEY, C.H. \& KANDEL, E.R. (1995). Molecular and Structural Mechanisms Underlying Long-Term Memory. In Gazzaniga, M. (ed.). The Cognitive Neurosciences. Cambridge, MIT Press.

BRANDÃO, M.L., ANSELONI, J.E., PANDÓSSIO, J.E., DE ARAÚJO, J.E. \& CASTILHO, V.M. (1999) Neurochemical Mechanisms of the Defensive behavior in the Dorsal Midbrain. Neuroscience \& Biobehavioral Reviews. 23 (6), p.863-75.

BURGESS, P.W., QUAYLE, A. and FRITH, C.D. (2001). Brain Regions Involved in Prospective Memory as Determined by Positron Emission Tomography. Neuropsychologia. 39 (6), p.545-55.

CHALMERS, D.J. (1996). The Conscious Mind. New York: Oxford University Press.

CHANGEUX, J.P. and DEHAENE, S. (2000). Hierarchical Neuronal Modeling of Cognitive Functions: From Synaptic Transmission to the Tower of London. International Journal of Psychophysiology. 35 (2-3), p.179-87.

CHANGEUX, J.P. and EDELSTEIN, S.J. (2001). Allosteric Mechanisms in Normal and Pathological Nicotinic Acetylcholine Receptors. Current Opinion in Neurobiology. 11 (3), p.369-77.

CRICK, F. (1984). Function of the Thalamic Reticular Complex: The Searchlight Hypothesis. In: Proceedings of the National Academy of Sciences. USA. 81, p.4586-90.

. (1994). The Astonishing Hypothesis. New York: Charles Scribner's/ Maxwell McMillan.

CRICK, F. \& KOCH, C. (1995). Are We Aware of Neural Activity in Primary Visual Cortex? In: Nature 375, p.121-3.

DAMASIO, A.R. (1996). Descartes' Error. New York: Grosset/Putnam.

DENNETT, D.C. (1991). Consciousness Explained. Boston: Little, Brown. 
D'ESPOSITO, M. \& GROSSMAN, M. (1996). The Physiological Basis of Executive Functions and Working Memory. The Neuroscientist 2, p.345-52.

EDELMAN, G.M. (1989). The Remembered Present: A Biological Theory of Consciousness. New York: Basic Books.

FRITH, C., PERRY, R. and LUMER, E. (1999). The Neural Correlates of Conscious Experience: an Experimental Framework. Trends in Cognitive Sciences 3 (3), p.105-14.

GALLUP, G.G. (1970). Chimpanzees: Self-Recognition. Science 167, p.86-7.

GOLDBERG, E. (1990). Higher Cortical Functions in Humans: The Gradiental Approach. In: E. Goldberg (ed.). Contemporary Neuropsychology and the Legacy of Luria. Hillsdale: Lawrence Erlbaum.

GOLDMAN-RAKIC, P.S. (1987). Circuitry of Primate Prefrontal Cortex and Regulation of Behavior by Representational Memory. In: V. Mountcastle (ed.). Handbook of Physiology, Section 1: The Nervous System, volume $\mathrm{V}$ : Higher Functions of the Brain, part 1. Bethesda: American Physiological Society.

GOODALE, M. and MILNER, A. (1992). Separate Visual Pathways for Perception and Action. Trends in Neuroscience, 15, p.20-5.

GRAY, C. \& SINGER, W. (1989). Stimulus-Specific Neuronal Oscillations in Orientation Columns of Cat Visual Cortex. Proceedings of the National Academy of Sciences USA 86, p.1.698-702.

GRAY, J.A. (1995). The Contents of Consciousness: A Neuropsychological Conjecture. Behavioral and Brain Sciences 18, p.659-722.

GRIFFIN, D.R. (1976). The Question of Animal Awareness. New York: Rockefeller University Press.

(1984). Animal Thinking. Cambridge: Harvard University Press.

GUIMARÃES, R. C. (1997). A Base Celular dos Ciclos de Memória. Em Soares, A. B. \& Gonzales, M.E.Q. (eds.). Encontro com as Ciências Cognitivas II. São Paulo/Campos dos Goytacazes: Ed. UNESP/UENF

HARDCASTLE, V. G. (1994). Psychology's Binding Problem and Possible Neurobiological Solutions. Journal of Consciousness Studies 1 (1), p.66-90.

HOBSON, J.A. (1994). The Chemistry of Conscious States. Boston: Back Bay Books.

JAMES, W. (1890). The Principles of Psychology. 2 volumes. New York: Dover (reedition)

JONIDES, J. (1995). Working Memory and Thinking. In: E.E. SMITH \& D.N. OSHERSON (eds.). An Invitation to Cognitive Science, vol.3: Thinking. Cambridge: MIT Press.
JONIDES, J \& SMITH, E.E. (1997). The Architecture of Working Memory. In: Rugg, M.D. (ed.). Cognitive Neuroscience. Cambridge: MIT Press.

KOHLER, S, \& MOSCOVITCH, M. (1997). Unconscious Visual Processing in Neuropsychological Syndromes: A Survey of the Literature and Evaluation of Models of Consciousness. In: Rugg, M.D. (ed.). Cognitive Neuroscience. Cambridge: MIT Press.

LASHLEY, K. (1960). The Neuropsychology of Lashley. New York: McGrawHill.

LEDOUX, J.E. (1994). The Amygdala: Contributions to Fear and Stress. Seminars in the Neurosciences 6, p.213-37

. (1996). The Emotional Brain. New York: Touchstone.

LIBET, B. (1987). Consciousness. In: Adelman, G. (ed.). Encyclopedia of Neuroscience. Boston: Birkhauser.

LIINAS, R.R. \& RIBARY, U. (1992). Rostrocaudal Scan in Human Brain: A Global Characteristic of the $40-\mathrm{Hz}$ Response During Sensory Input. In: Basar, E. and Bullock, T. (eds.). Induced Rhythms in the Brain. Boston: Birkhouser.

. (1994). Perception as an Oneiric-like State Modulated by the Senses. In: C. E. KOCH and DAVIS, J. L. (eds.). Large-Scale Neuronal Theories of the Brain. Cambridge: MIT Press.

LOGOTHETIS, N.K. \& SCHALL, J. (1989). Neuronal Correlates of Subjective Visual Perception. Science 245, p.761-3.

LYCAN, W.G (1987). Consciousness. Cambridge: MIT Press. (1996). Consciousness and Experience. Cambridge: MIT Press

LURIA, A.R. (1973). The Working Brain. Transl, by B. Haigh. New York: Basic Books.

MCLEAN, P.D. (1990). The Triune Brain in Evolution. New York: Plenum Press. MILNER, A. D. \& GOODALE, M. (1995). The Visual Brain in Action. Oxford: Oxford University Press.

MILNER, P.M. (1996). Neural Representations: Some Old Problems Revisited. Jnl. of Cognitive Neuroscience, 8:1, p.69-77.

NEWMAN, J. \& BAARS, B.J. (1993). A Neural Attentional Model for Access to Consciousness: A Global Workspace Perspective. Concepts in Neuroscience, 4:2, p.255-90.

PANKSEPP, J. (1999). Affective Neuroscience: the Foundations of Human and Animal Emotions. New York: Oxford University Press.

PENFIELD, W. \& BOLDREY, E. (1937). Somatic Motor Sensory Representation in the Cerebral Cortex of Man as Studied by Electrical Stimulation. Brain 60, p.389-443. 
PEREIRA JR., A. (1990). A Percepção do Tempo em Husserl. Trans-FormAção 13, São Paulo: UNESP, p.73-84.

(1998). The Degrees of Consciousness. In Ciencia e Cultura - Journal of the Brazilian Society for the Advancement of Science 50 (2/3), p.129-34.

(1999). Representation in Cognitive Neuroscience. In: A. Riegler, M. Peschl and von Stein, A. (orgs.). Understanding Representation in the Cognitive Sciences: Does Representation Need Reality? New York, Boston, Dordrecht: Kluwer Academic/Plenum Publishers.

. (2000). A Possible Role for Action Schemes in Mirror Self-Recognition. Revista de Etologia 2, p.37-54.

(2001a). Coexisting Spatial and Temporal Scales in Neuroscience. Minds and Machines 11 (4), p.457-65.

(2001b). The Quantum Mind/Classical Brain Problem. Informação e Cognição, vol. 3, n. 3. Meio de divulgação digital: http://www.marilia. unesp.br/divulgacoes/revista/index.htm

POSNER, M.I. (1994). Attention: The Mechanisms of Consciousness. Proceedings of the National Academy of Sciences 91, p.7.398-403.

. (1995). Attention in Cognitive Neuroscience: an Overview. In M. S Gazzaniga (ed.). The Cognitive Neurosciences. Cambridge: MIT Press.

RAINER, G., RAO, S.C. and MILLER, E.K. (1999). Prospective Coding for Objects in Primate Prefrontal Cortex. Journal of Neuroscience 19 (13), p.5.493-505.

ROCHA, A., PEREIRA JR., A. \& COUTINHO, F. (2001). NMDA Channel and Consciousness: From Signal Coincidence Detection to Quantum Computation. Progress in Neurobiology 64 (6), p.555-73.

ROSENTHAL, D. (1986). Two Concepts of Consciousness. Philosophical Studies 94, p.329-59.

ROY JOHN, E., EASTON, P. \& ISENHART, P. (1997). Consciousness and Cognition May Be Mediated by Multiple Independent Coherent Ensembles. Consciousness and Cognition 6, p.3-39.

SCHACTER, D.L. (1989). On the Relation Between Memory and Consciousness: Dissociable Interactions and Conscious Experience. In: Henry L. Roediger, III \& Fergus I. M. Craik (eds.). Varieties of Memory and Consciousness. Hillsdale: Lawrence Erlbaum Asssociates.

SHANON, B. (1997). Three Types of Consciousness. In: M.E.Q. Gonzales, C.A. Lungarzo, C.B. Milidoni, A. Pereira Jr. and M.B. Wrigley (eds.). Encontro com as Ciências Cognitivas. Marilia: Universidade Estadual Paulista.

SMITH, E.E. \& JONIDES, J. (1997). Working Memory: A View from Neuroimaging. Cognitive Psychology 33, p.5-42.
SMYTHIFS, J. (1997). The Functional Neuroanatomy of Awareness, with a Focus on the Role of Various Anatomical Systems in the Control of Intermodal Attention. Consciousness and Cognition 6(4), p.455-81.

SQUIRE, L.R. (1992). Memory and the Hippocampus: A Synthesis From Findings With Rats, Monkeys and Man. Psychological Review 99, p.195231.

STREHLER, B. L. (1991). Where is the Self? A Neuroanatomical Theory of Consciousness. Synapse 7, p.44-91.

STUSS, D.T. \& BENSON, D.F. (1990). The Frontal Lobes and Language. In: E Goldberg (ed.). Contemporary Neuropsychology and the Legacy of Luria. Hillsdale: Lawrence Erlbaum.

STUSS, D.T., ESKES, G.A. \& FOSTER, J.K. (1994). Experimental Neuropsychological Studies of Frontal Lobe Functions. In: F. Boller and J. Graffman (eds.), Handbook of Neuropsychology vol.9. New York: Elsevier Science.

TEUBER, H.L. (1960). Perception. In: J. FIELD, H.W. MAGOUN, and V.E HALL (eds.). Handbook of Physiology, sect. I, vol. III. Washington: American Physiological Society, p.1.595-668.

TONONI, G., EDELMAN, G.M. and SPORNS, O. (1998). Complexity and Coherency: Integrating Information in the Brain. Trends in Cognitive Science 12 (2), p.474-84.

UNGERLEIDER, L. G. and HAXBY, J.V. (1994). "What" and "Where" in the Human Brain. Current Opinion in Neurobiology 4, p.157-65.

VON UEXKULL, J. (1934). Os Mundos dos Animais e dos Homens. Tradução Portuguesa. Lisboa: Enciclopedia LBL

WEISKRANTZ, L. (1997). Consciousness Lost and Found. Oxford: Oxford University Press.

YOUNG, A.W. (1994). Neuropsychology of Awareness. In: Revonsuo, A. and Kamppinen (eds.). Consciousness in Philosophy and Cognitive Neuroscience. Hiilsdale (NJ), Lawrence Erlbaum, p.173-204. 